\title{
Carcinovic cohort: prognostic factors of death in HIV/HCV coinfected patients with hepatocellular carcinoma (HCC)
}

\author{
M Gelu-Simeon*, M Lewin, R Sobesky, M Ostos, T Bayan, F Boufassa, L Meyer, A Persoz, E Teicher, H Fontaine, \\ D Salmon-Céron, O Seror, J-C Trinchet, J-C Duclos-Vallée
}

From International Symposium HIV and Emerging Infectious Diseases 2014

Marseille, France. 21-23 May 2013

\section{Background and aim}

We have previously reported a more advanced radiological presentation in $\mathrm{HIV}+/ \mathrm{HCV}+$ than $\mathrm{HIV}-/ \mathrm{HCV}+$ patients (pts). The aim of our study was to define prognostic factors of death in HIV+/HCV+ pts with HCC.

\section{Methods}

Cases of $\mathrm{HCC}$ in $\mathrm{HIV}+/ \mathrm{HCV}+$ pts were obtained from the 3 ANRS Prethevic, HepaVih and CirVir cohorts. Imaging was reviewed according to EASL criteria.

\section{Results}

Fifty HIV+/HCV+ coinfected pts ( $\mathrm{n}=44$ men $(88 \%)$, median age 50 years [40-74], median CD4 cell count $334 / \mathrm{mm} 3$ [58-1621], $\mathrm{n}=28$ Child A cirrhosis (60\%)) developed HCC. Thirty-one (63\%) pts presented cirrhosis decompensation before HCC diagnosis. At HCC diagnosis, median serum aFP was 20.4 [1.9-198,900] ng/ml, 38 (76\%) pts had a nodular tumor (median main diameter 23.5 [11-70] cm) and $12(24 \%)$ pts an infiltrating form $(62.5[10-130] \mathrm{cm})$, $\mathrm{p}=0.007$. Tumor portal thrombosis was diagnosed in 14 (28\%) pts. A curative or a palliative procedure was further performed in $22(44 \%)$ pts and 20 (40\%) pts, respectively. The 2-years and 4-years overall survival rates were $51 \%$ and $28 \%$, respectively. Age $(\mathrm{p}=0.0005)$, infiltrating or nodular tumor $(\mathrm{p}=0.0009)$ and tumor portal thrombosis $(\mathrm{p}=0.004)$ were associated to survival. In a Cox model, two prognostic factors of deaths were found: prior episode of cirrhosis decompensation (aRR 11.43 [3.01-43.34], $\mathrm{p}=0.0003$ ) and tumor portal thrombosis (aRR 4.66 [1.19-18.27], $\mathrm{p}=0.03$ ), adjusted on age, CD4 cell count and the therapeutic strategy for HCC.

\footnotetext{
Paul Brousse Hospital, Villejuif, France
} 